\title{
https://doi.org/10.48009/1_iis_2006_273-277 \\ ANALYSIS OF ENTERPRISE SOFTWARE DEPLOYMENT IN ACADEMIC CURRICULA
}

\author{
Roger L. Hayen, Central Michigan University, roger.hayen@cmich.edu \\ Frank A. Andera, Central Michigan University, frank.andera@ cmich.edu
}

\begin{abstract}
The integration of enterprise software (ES) into business and related college curricula began in 1996. Since then, a number of universities have taken different paths in the integration of ES into their curricula. A framework for curriculum integration is multi-dimensional. The most frequently reported integration effort is inclusion of ES in the introductory IS course, which is required of most business students. Limited arrangements of courses that transcend the business curriculum in the integration of ES have been reported. Several different approaches to the design and delivery of learning modules have been describe that foster utilization across universities curricula. However, much remains to be done before ES course content reaches maturity by evolving to the level of being integrated into a course-in-a-box for those disciplines embracing ES in their curricula.
\end{abstract}

Keywords: Enterprise Software, ES, Enterprise Resource Planning, ERP, SAP R/3 System, Curriculum Integration, Curriculum Framework, Curriculum Design

\section{INTRODUCTION}

The purpose of this research is to provide information for making informed choices in integrating enterprise software into a business or related curriculum. Enterprise software encompasses enterprise resource planning (ERP) systems [1, 12], which are comprehensive, packaged software that integrate the complete range of business processes and functions in order to provide a holistic view of business within a single information system (IS) technology architecture. These systems encompass the core transaction processing activities of a business enterprise, which is more than just resource planning. To indicate this expansive capability, this software is referred to here as enterprise software (ES). Vendors of ES include SAP AG, PeopleSoft, Oracle, J.D. Edwards, and Baan. The widespread use of ES has increased the need for students with knowledge of this software. In an effort to meet this need, SAP AG initiated the SAP University Alliance Program (UAP) in North America in 1996 [3, 14]. That program now encompasses approximately 200 universities. The primary purpose of the SAP UAP is to make students more knowledgeable while concurrently providing faculty with the opportunity to employ cutting-edge information technology [8].

ES integration into academic curricula poses many choices, which range from "do nothing" to undertaking extensive integration with considerable effort in the development of course materials to support that integration [10]. However, the proliferation of research in integrating ES into the business curriculum [2] would indicate that some integration is appropriate. The underlying questions then are: What is being done in ES curriculum integrations? What should be done at your academic institution? Typically, the goal is to use ES technology as a "tool" to help teach business concepts [7]. The purpose here is to assist you in assessing options to determine where your curriculum is and to help determine its future direction

\section{FRAMEWORKS}

A framework is useful in that it supports organizations in gaining a perspective on the field of ES and serves as a powerful means of providing focus and improving the effectiveness of a curriculum. For ES, frameworks have been postulated at several levels that encompass an individual course, a curriculum of a business discipline or college, the extent of integration, and the availability of course materials.

A curriculum integration framework [29] describes the infrastructures for undertaking the integration of ES into the curriculum. An integrated ES model curriculum framework [10] arranges courses into three primary categories which are All Students, IS Program, and Functional Area. All Students are the CBK courses, required of all business students, and other courses in ES designed for all students, independent of their major. IS Program courses are those specialized information technology and application design courses for both a major and minor in IS. Courses in this category are taken by both IS majors and students in functional areas who desire an IS specialist competency or minor, and they 
frequently follow a general IS curriculum model [16]. Functional Areas courses are those that integrate ES applications with functional area concepts and meet a minimum content requirement for an ES component course, wherein ES concepts are entwined with the functional area knowledge. An example of this integration would be a human relations compensation course in which the cases that support the concepts are ES cases and include a hands-on ES component that supports the compensation concepts. Generally, students would follow this curriculum framework by taking initial classes in the All Students category and then proceed further, depending on their interest.

Applying the criteria established by SAP America, an ES component course is one in which 20 percent or more of the content is related to the concepts and/or applications of ES [7]. The extent of course integration can vary from just mentioning ES, SAP $\mathrm{R} / 3$ and ERP in one or two course lectures to the extent of encompassing the entire course, such as ERP Configuration and Use. In this situation, the course easily could have 100 percent ES content through the combination of business concepts and hands-on experience in the course.

When will ES course integration reach maturity? One means of recognizing this is when ES has been integrated in to one or more courses as a fundamental component of a course-in-a-box for ES component courses. A course-in-a-box is one in which a plethora of ancillary materials are provided with the course textbook. Loudon and Loudon [13] provide an example of one these for a management information systems course. You have nearly every conceivable resource current technology can provide to support the delivery of a course. Essentially, all you need to do is choose the textbook, and its all there. A coursein-a-box is what is expected by faculty for most common body of knowledge (CBK) courses and many of the other courses in the business curriculum. A course-in-a-box provides a dimension for comparing ES integration into the business curriculum.

\section{MULTI-DIMENSIONAL CURRICULUM INTEGRATION}

The integration of ES into the curriculum is multidimensional, as reported in the literature. Many creative methods have been used in moving forward with institution and discipline integration. These approaches include the following:

1. Single course

a. With some ES content

b. With 100 percent ES content
2. Several courses

a. With some ES content in the functional business areas

b. With extensive ES content in the management information systems area

3. Hands-on, experimental learning cases

a. Used with a single course.

b. Used in several courses.

4. ES content modules that are used in one or more courses.

5. Special certification courses for increased student knowledge confirmation

6. Delivery mode of course instruction

Of course, these approaches are not mutually exclusive. For example, ES content modules may have their availability enhance by being web-based. Each of these six categories is examined next.

\section{Single Course}

A number of individual courses, which integrate ES into a particular course, have been described $[4,5,6$, 9]. Some of these courses indicate results of student learning and satisfaction, which were measured in those courses [5]. Generally, students have reported satisfaction with these experiences.

McCombs and Sharifi [13] describe their experience in implementing a single course using Oracle Financials as their selected ERP software. This course was designed for accounting students. Objectives of the course included understanding the fundamentals of business process reengineering (BPR) and ERP systems; providing hands-on experience; and examining issues related to the implementation of complex ERP systems. They report that significant effort was involved in developing this course. The course requires continuous time and learning involvement by one or more interested faculty to keep it going.

Gust and Hayen [5] describe the integration of the SAP ES into the CBK course, an introduction to business computing. The objectives of integrating ES into the course at this All Student level in the curriculum is to make students aware of this type of software and introduce them to its best business practices process integration and hands-on operation. They surveyed over 300 students enrolled in this course to determine students' reactions to the exploration of the software. Generally, students report a high level of satisfaction with the ES component of this course and the manner in which its integration was achieved. Overall, this experience relates the integration of ES into a single course in 
the business curriculum, which appears to be an All Students course.

\section{Several Courses}

Corbit and Mensching [3] describe the experiences at California State University (CSU) Chico in implementing the SAP R/3 System in their College of Business Curriculum. CSU Chico was the first university in the U.S. to undertake this implementation. They present 18 courses in accounting, finance, production management, and management information system that include an SAP $\mathrm{R} / 3$ component. However, the extent of ERP integration in each course is not indicated, rather it is presented as a monolithic curriculum. They present a menu of ES content courses. Like a menu at your favorite restaurant, it is likely a major would choose only a subset of all the courses on the menu. On the other hand, Hayen and Andera [7] present a set of 16 undergraduate and graduate ES component courses that are included in the curriculum of their business college. They include courses that encompass the All Students, Functional Areas, and IS Program of the curriculum framework presented above.

\section{Experiential Learning Cases}

A number of case scenarios have been created and used in ES courses [4, 6]. Hajnal and Riordan [6] describe a single course which they have developed. Their Introduction to Information Systems is a required CBK course. For active learning, they use a case company (petPRO) which they have created. In the development of this course, they implement a pedagogy style that includes role playing and active learning with ES. A course web site provides a traditional repository of course materials that include the syllabus, classroom presentation materials, detailed assignment descriptions, and course management content. Their pedagogy is independent of their selected textbook. However, this appears as a pedagogy that works for them, but is does not contain plug-and-play components transferable to others.

\section{ES Content Modules}

Watson and Scheider [15] describe a series of 10 KnowDules (or knowledge modules) developed for use at their university. These $10 \mathrm{KnowDules}$ are each planned for use in a number of sessions or lectures. The 10 KnowDules provide material for 45 sessions. Their university is a member of the SAP UAP so their KnowDules are for the SAP R/3 System. They provide a general overview of how their KnowDules may be used in information systems, decision sciences, accounting, management, and marketing courses. However, this is a general mapping of KnowDule topics to courses. A more specific application of KnowDules in courses is left to the determination of each instructor. This material does provide the foundation for either a single course in ES or its integration into a number of courses.

Hayen and Holmes [9] report the results of using web-based training (WBT), online lesson modules in an introductory ES course. The modules were developed around the SAP R/3 System. Overall, the students surveyed reported their satisfaction with this method of delivering ES concepts to support their learning in a convenient asynchronous, readily available format.

\section{Certification Programs}

At the authors' university, each student completing an ES component course is provided with a certificate of completion from the university. Upon completion of three of these courses, they are then eligible for a certificate of completion that is granted by both the university and SAP UAP. Although this certificate is not an official SAP consultant certification, it does provide the student with a level of achievement recognized by SAP UAP. Students clearly strive to obtain this SAP sanctioned certificate across the various business majors.

Hayen and Cappel [8] describe the SAP R/3 Process Integration Academy, also known as "SAP boot camp." The boot camp has been conducted by SAP America at several UAP member institutions for a number of years. This boot camp is delivered by SAP consultants and culminates in students taking an official SAP certification examination in process integration. Overall, this has been a very well received and effective program, although, this is specifically a not-for-credit educational activity.

\section{Delivery Methods}

Holmes and Hayen [9] describe the design and development of a web-based course, which is an introduction to ES using the SAP R/3 System. This course consisted of a number of WBT, online lessons and a web-based discussion forum for additional active student learning.

Hayen et al [11] describe a virtual classroom that houses web-based, e-course materials for SAPrelated education. While arranged as a "virtual classroom," the entire architecture or selected elements of it can be deployed in integrating ES into 
a curriculum. This architecture is compatible with the plug-and-play curriculum of SAP America. Plugand-play curriculum [14] provides course support through the availability of proven curriculum materials and exercises in certain topics areas. These can be altered and adopted to support many different curriculum objectives.

\section{RESEARCH ANALYSIS}

A total of 52 ES curriculum integration publications were found by conducting a comprehensive literature search. Each of these provided a substantial description of the particular integration effort. The characteristics of each effort were recorded, based on parameters derived from the frameworks and the perspectives of the multi-dimensional curriculum integration. Microsoft Excel was used to analyze these data. No quota or other preset limit was established for the number of integration efforts for any particular characteristic included in this investigation. Therefore, the values for these major groupings of ES curriculum undertakings are consider representative.

Of the reported integration efforts, 11 percent were determined to be a single course with some ES content, 42 percent were identified as a single course with 100 percent ES content, 35 percent were classified as several course with some ES content in functional business areas, and 13 percent were several course with extensive ES content in the MIS area as indicated in Figure 1. The results shown in Figure 1 are identified as follows:

$\mathrm{A}=$ Single course with some ES content

$\mathrm{B}=$ Single course with 100 percent ES content

$\mathrm{C}=$ Several courses with some ES content in functional areas

$\mathrm{D}=$ Several courses with extensive content in the MIS area

$\mathrm{E}=$ Hands-on learning used with a single course

$\mathrm{F}=$ Hands-on learning used in several courses

$\mathrm{G}=$ Special certification course

In this analysis, an individual curriculum development effort could be counted in more that one category, such as a single course with some ES content that used hands-on learning. Considering course efforts with more or less than 20 percent ES content, curricula with a single course were found to have 82 percent with 20 percent or more ES content (Figure 2), whereas curricula with several courses were identified as having 95 percent with 20 percent or more ES content . For the delivery mode, 81 percent of curriculum implementation used a traditional method for delivering courses. Overall, these results indicate the most frequently occurring ES curriculum integration undertaking was a single course with 100 percent ES content that is delivery by traditional teaching methods.

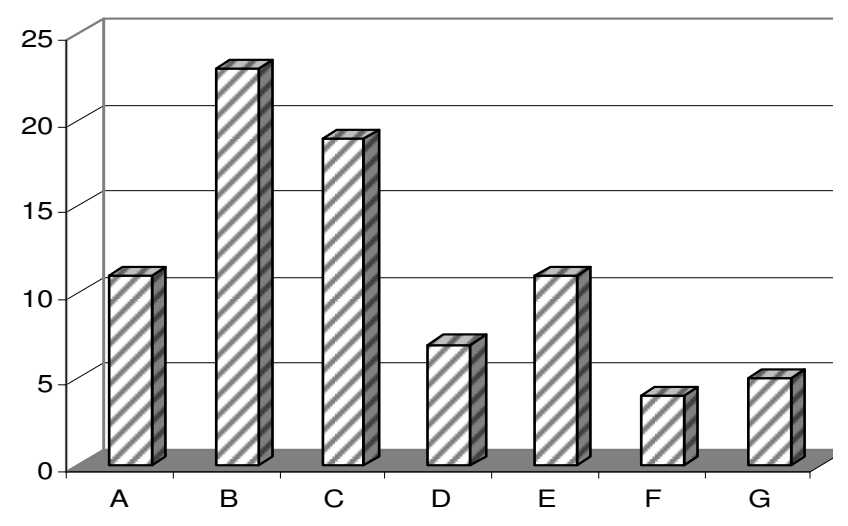

Figure 1. ES Multi-Dimensional Curriculum Integration

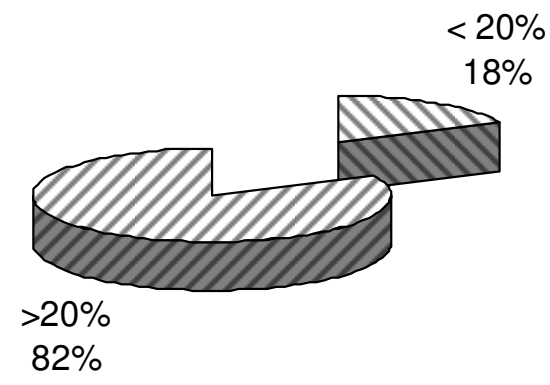

Figure 2. Single Courses with $<20 \%$ and $>20 \%$ of ES Content

While a number of individual course endeavors have been undertaken $[4,5,6,9]$, the literature search did not reveal any course-in-the-box alternatives for ES component courses. When ES reaches the level of being integrated into the business curriculum to the extent that each ES component course is a course-ina-box, then the integration of ES into the business curriculum will have reached a mature level. Much remains to be done in the development of ES component courses and the creation of various course materials before that maturity is attained. In the meantime, example courses, curriculum, and case materials are merely current resource materials that assist in the movement of this integration toward maturity. Curriculum integration extends beyond the initial integration. It is a continuous improvement 
process that will be repeated many times in the coming years.

\section{SUMMARY AND CONCLUSION}

A variety of alternatives are being used to integrate ES into the business and related curriculum. This integration is necessary in the continuous evolution of a contemporary curriculum that provides education determined to be important by the organizations hiring graduate of these educational institutions. Several frameworks provide guidance for curriculum integration with consideration provided for courses designed for All Students, the Functional Areas, and IS Programs. The actual integration effort to date is multi-dimensional in the approaches of curriculum integration. By far, the effort, which has been reported most frequently, is a single course for All Students, which is an introduction to IS. Two college curriculums have been reported that present collections of ES component courses, which transcend most of a business college curriculum. Learning modules and web-based delivery provided a method for making ES curriculum materials more readily available within a university and to the general educational discipline, but this method is used much less frequently than traditional course delivery. However, the current status of curriculum integration is such that ES component courses have not reached the state of delivery afford to a course-ina-box. Therefore, the early adopters and developers of integrated ES curriculums expend considerable effort in integrating ES into their curriculums.

\section{REFERENCES}

1. Andera, F. \& D. W. Derringer (Fall 1998). SAP: Implications for Computer Information Systems, Journal of Computer Information Systems, 39(1), 72-75.

2. Antonucci, Y. L., G. Corbitt, G. Stewart, \& A. L. Harris (2004). Enterprise Systems Education: Where Are We/ Where Are We Going? Journal of Information Systems Education, 15(3), 227 234.

3. Corbit, G. \& J. Mensching (2000). Integrating SAP R/3 into a College of Business curriculum: Lessons learned, Information Technology and Management, 1(4), 247-258.
4. Dolphin Group (2002). SAP Consulting and Education: Dolphin 200 - Configuration and Integration Workshop. Self-published.

5. Gust, D. D. \& Hayen, R. L. (1999). Including SAP Enterprise Software in the Introductory Business Computer Course, Proceedings of ISECON, October 1999.

6. Hajnal, C. A. \& R. Riordan (2004). Exploring Process, Enterprise Integration and E-business Concepts in the Classroom: The Case of petPRO, Journal of Information Systems Education, 15(3), 267-275.

7. Hayen, R. L. \& Andera F. J. (2003). Assessment of Student Satisfaction with SAP R/3 Component Courses, Issues in Information Systems, 4(1), 150-156.

8. Hayen, R. L. \& J. J. Cappel (2001). Certification in Enterprise Software: An SAP R/3 University Alliance Program Experiment, Issues in Information Systems, 2, 132-138.

9. Hayen, R. L. \& M. C. Holmes (1998). SAP Enterprise Software: A Web-Based Course, Proceedings, International Association for Computer Information Systems, October 1998.

10. Hayen, R. L., J. J. Cappel, \& M. C. Holmes (Winter 1999-2000). A Framework of SAP R/3 Enterprise Software Instruction, Journal of Computer Information Systems, 40(2), 79-85.

11. Hayen, R. L., M. C. Holmes, \& J. J. Cappel (2000). An SAP R/3 Virtual Classroom for Asynchronous Collaborative and Experiential Learning, Issues in Information Systems, 1, 189195.

12. Laudon, K. C. \& J. P. Laudon, (2004). Management Information Systems, 8th ed. Upper Saddle River, NJ: Prentice-Hall.

13. McCombs, G. B. \& M. Sharifi. (Winter 20022003). Design and Implementation of an ERP Oracle Financials Course, Journal of Computer Information Systems, 43(2), 71-75.

14. SAP AG (2001). What's New with the SAP Educational Alliance Program in the U.S. Philadelphia, PA: SAP America, Inc. September 2001.

15. Watson, E. E. \& H. Schneider (1999). Using ERP Systems in Education, Communications of the Association for Information Systems, 1(9), February 1999, 1-34. 